\title{
Synthesis of 3-amino-2-(2-chlorophenyl)quinazolin-4(3H)-one by Conventional Heating and Microwave Irradiation
}

\author{
Luthfi Ahmad Muchlashi ${ }^{*}$ \\ ${ }^{1}$ Department of Phramacy, Faculty of Medicine and Health Sciences, UIN Maulana Malik Ibrahim, \\ Malang, Indonesia \\ *Corresponding author. E-mail: luthfimuchlasi@gmail.com
}

\begin{abstract}
This study aims to compare conventional heating with microwave irradiation in order to obtain the optimal method for 3-amino-2-(2-chlorophenyl)quinazolin-4(3H)-one synthesis. The synthesis of these compounds requires long-term exposure to heat. About 10 hours were required for the reaction using conventional heating, while it took only 5 minutes using microwave with 800 watts of power. It was found that there was an improvement in percent yields of 3-amino-2-(2-chlorophenyl)quinazolin$4(3 \mathrm{H})$-one from $79 \%$ to $87 \%$ by using reflux and microwave irradiation, respectively. Therefore, microwave-assisted method was a quicker and higher $\%$ yield compared to reflux method for 3-amino-2-(2-chlorophenyl)quinazolin-4(3H)-one synthesis.
\end{abstract}

Keywords: quinazoline, conventional synthesis, microwave-assisted synthesis

Submitted: December $1^{\text {st }} 2021 \mid$ Accepted: December $14^{\text {th }} 2021 \mid$ Published: December $31^{\text {st }} 2021$

\section{Introduction}

Quinazoline is an aromatic bicyclic compound with two nitrogen atoms in its structure. It consists of two sixmembered aromatic rings fused together, which are benzene and pyrimidine rings. Compound with quinazoline ring system has pharmacodynamic versatility, that many of researcher developing this compound as a promising drugs[1].

Due to its potency, quinazoline compound from the starting material of anthranilic acid was synthesized. The synthesis of 3-amino-2-phenylquinazolin-4(3H)-one from anthranilic acid had been widely practiced[2-4]. Therefore, it is useful to develop a new method for the synthesis of 3-amino2-(chlorophenyl)quinazolin-4(3H)-one, which is simple and environmentally friendly and given unsatisfactory yields..

The wide applicability of microwave irradiation in chemical reaction enhancement is due to its high reaction rates, formation of cleaner products, and operational simplicity [5]. This forms the basis of this study aimed to compare conventional heating with microwave irradiation.

\section{Materials and Methods}

All chemicals were supplied by Sigma Aldrich and Merck. The reaction conditions were optimized using pre-coated thin layer chromatography aluminum sheets (silica gel GF254) with $0.2 \mathrm{~mm}$ layer thickness (E. Merck). Melting points of the synthesized compounds were determined with Electrothermal melting point apparatus. IR spectra were obtained using Perkin Elmer Spectrum One spectrophotometer using $\mathrm{KBr}$ disks. 1H-NMR and 13C-NMR spectra were obtained on JEOL JNM-ECS 400 (1H-NMR: 400 MHz, 13C-NMR: 100 $\mathrm{MHz}$ ) instrument from Institute of Tropical Disease Airlangga University. DMSO-d6 was used as solvent for 1H- NMR and
13C-NMR analysis. Chemical shifts were measured in ppm downfield from tetramethylsilane, the $\mathrm{J}$ values were given in Hz. Abbreviations used were as follows: s (singlet), d (doublet), $\mathrm{t}$ (triplet), dd (double of doublet), td (triple of doublets), and $\mathrm{m}$ (multiplet). The reaction was executed using commercial microwave oven (Samsung ME731K 800W).

\section{Synthesis of 2-(2-chlorophenyl)-4H-benzo[d][1,3]oxazin-4- one}

The synthesis of 2-(2-chlorophenyl)-4H-benzo[d][1,3] oxazin-4-one (3) derived from Anthranilic acid. Anthranilic acid (1) was dissolved in pyridine, then 2-chlorobenzoyl chloride (2) was slowly added into this solution at $0 \mathrm{oC}$ with constant stirring. The reaction mixture was stirred for 30 minutes using mechanical stirrer at room temperature. The semisolid mass obtained was treated with sodium bicarbonate $10 \%$ solution and diluted with water until the effervescence ceased. The solution was filtered and washed with water to remove inorganic material and pyridine. The solid was dried and recrystallized using diluted ethanol.

\section{Synthesis of 3-amino-2-(2-chlorophenyl)quinazolin-4(3H)- one}

The synthesis of 3-amino-2-(2-chlorophenyl)quinazolin$4(3 \mathrm{H})$-one (4) derived from 2-(2-chlorophenyl)-4H-benzo[d] [1,3]oxazin-4-one. 2-(2-chlorophenyl)-4H-benzo[d][1,3] oxazin-4-one $(5 \mathrm{mmol})$ was dissolved in $10 \mathrm{ml}$ pyridine, then added dropwise into $5 \mathrm{ml}$ pyridine solution containing hydrazine hydrate $(10 \mathrm{mmol})$. The reaction mixture was stirred constantly for 30 minutes at room temperature. In this step, two different methods were used, which were conventional heating and microwave irradiation. By conventional heating, reaction 
mixture was heated under reflux $(115 \mathrm{oC})$ for 10 hours, and by microwave irradiation, reaction mixture was irradiated using microwave $(800 \mathrm{w})$ for 5 minutes. Then, the results obtained were poured into water (containing a few drops of $\mathrm{HCl}$ ). The separated solid was filtered and washed repeatedly with water. It was dried and recyrystallized using dilluted ethanol.

\section{Results}

\section{Synthesis of 2-(2-chlorophenyl)-4H-benzo[d][1,3]oxazin-4-}

one

The results of 2-(2-chlorophenyl)-4H-benzo[d][1,3] oxazin-4-one (3) synthesis were as follows: Obtained percent yield was 92\%; MP 141-142 oC; IR ( $\mathrm{KBr}, \mathrm{vmax}, \mathrm{cm}-1)$ : 1769 $(\mathrm{C}=\mathrm{O}$ lactone $) ; 1625(\mathrm{C}=\mathrm{N}) ; 1315(\mathrm{C}-\mathrm{N}) ; 1474$ dan 1605 $(\mathrm{C}=\mathrm{C}$ aromatics); 3036 (sp2 C-H); $762(\mathrm{C}-\mathrm{Cl}) ; 1272$ (C-O-C). 1H-NMR (DMSO-d6) $\delta$, ppm : 8,16 (1H, dd, J=8Hz, Ar-H), 7,96 (1H, td, J=7,8Hz; 1,6Hz, Ar-H), 7,90 (1H, dd, J=7,2Hz,
Ar-H), 7,72-7,58 (4H, m, Ar-H), 7,52 (1H, dt, J=7,2Hz; 1,2Hz, Ar-H). 13C-NMR (DMSO-d6) $\delta$, ppm: $\delta, 159,3(\mathrm{C}=\mathrm{O}) ; 156,3$; 146,$4 ; 137,6 ; 133,4 ; 132,3 ; 132,2 ; 131,2 ; 130,7 ; 129,9 ; 128,6$; 128,$1 ; 127,7 ; 117,4$

\section{Synthesis of 3-amino-2-(2-chlorophenyl)quinazolin-4(3H)- one}

The results of 3-amino-2-(2-chlorophenyl)quinazolin$4(3 \mathrm{H})$-one synthesis were as follows: Obtained percent yield was $87 \%$ (microwave) and $79 \%$ (reflux) ; MP 154-155 ${ }^{\circ} \mathrm{C}$; IR (KBr, vmax, cm-1) $1672(\mathrm{C}=\mathrm{O}$ amide); $1672(\mathrm{C}=\mathrm{N}) ; 1338$ $(\mathrm{C}-\mathrm{N}) ; 1471$ dan $1614(\mathrm{C}=\mathrm{C}$ aromatic); $3012(\mathrm{C}-\mathrm{H}) ; 772(\mathrm{C}-$ $\mathrm{Cl}) ; 3461$ and $1614(\mathrm{~N}-\mathrm{H}) .1 \mathrm{H}-\mathrm{NMR}$ (DMSO-d6) $\delta$, ppm 8,20 $(1 \mathrm{H}, \mathrm{dd}, \mathrm{J}=8 \mathrm{~Hz}, \mathrm{Ar}-\mathrm{H}), 7,84(1 \mathrm{H}, \mathrm{dt}, \mathrm{J}=7,2 \mathrm{~Hz} ; 1,2 \mathrm{~Hz}, \mathrm{Ar}-\mathrm{H})$, 7,69 (1H, d, J=8Hz, Ar-H), 7,59-7,42 (5H, m, Ar-H), 5,51 (2H, s, NH2). 13C-NMR (DMSO-d6) $\delta$, ppm: 161,5 (C=O); 154,9; 147,$2 ; 135,4 ; 135,0 ; 132,0 ; 131,1 ; 130,6 ; 129,3 ; 128,0 ; 127,8$; 127,$4 ; 126,6 ; 121,1$.<smiles>Nc1ccccc1C(=O)O</smiles>
1<smiles>O=c1oc(-c2ccccc2Cl)nc2ccccc12</smiles>

3<smiles>O=C(Cl)c1ccccc1Cl</smiles>

2<smiles>NN</smiles>
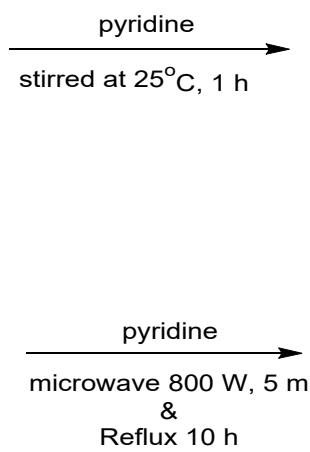<smiles>O=c1oc(-c2ccccc2Cl)nc2ccccc12</smiles>

3<smiles>Nn1c(-c2ccccc2Cl)nc2ccccc2c1=O</smiles>

4

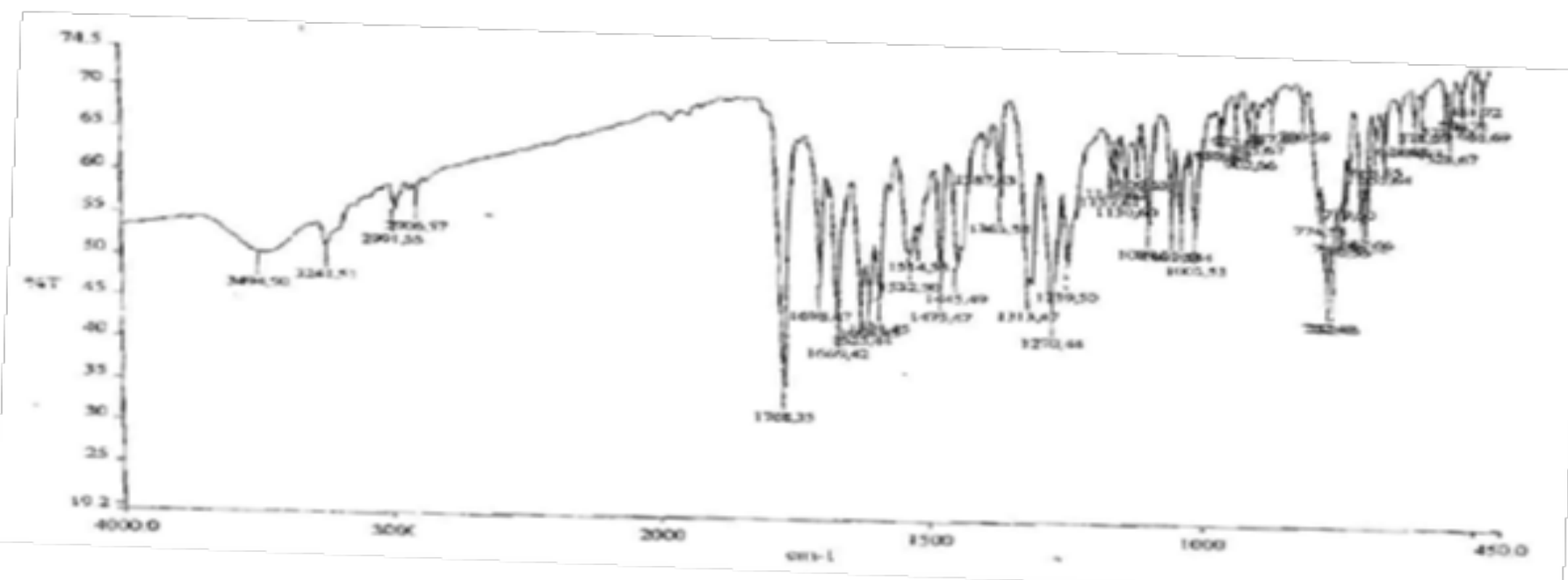

Figure 1. Scheme 1 Synthesis route for 3-amino-2-(2-chlorophenyl)quinazolin-4(3H)-one (A). IR spectra of 2-(2-chlorophenyl)-4H-benzo[d][1,3] oxazin-4-one (B) 


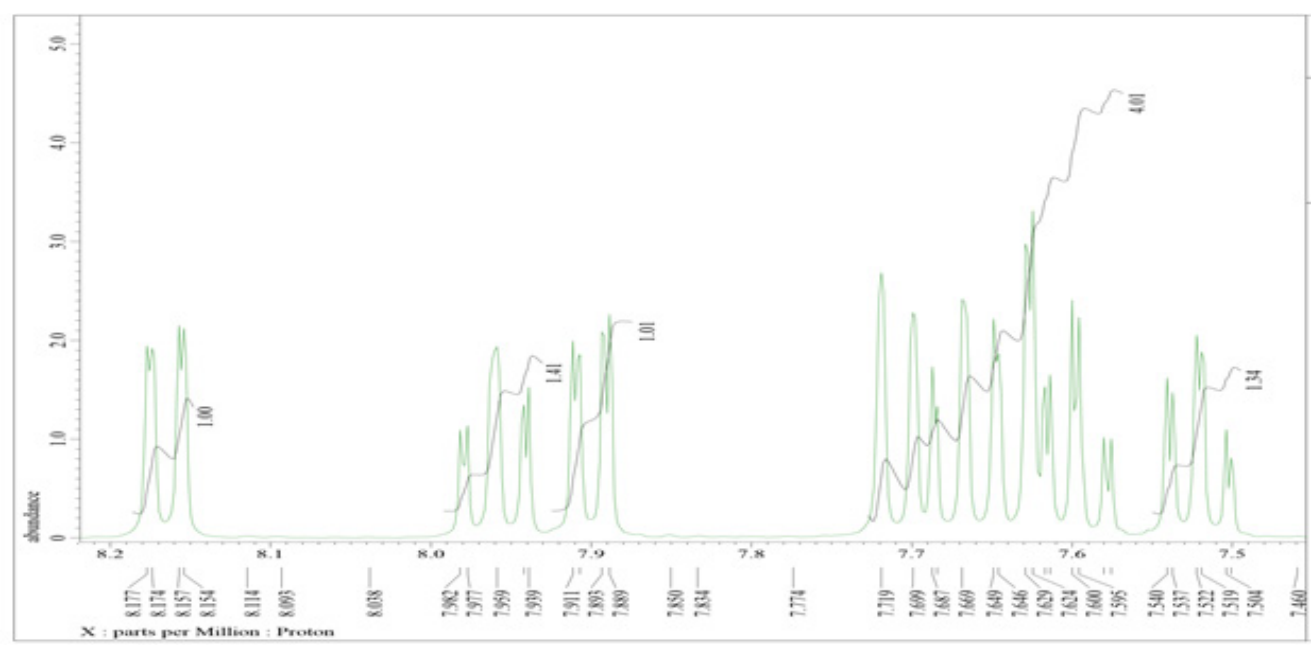

Figure 2. NMR-H spectra of 2-(2-chlorophenyl)-4H-benzo[d][1,3]oxazin-4-one in DMSO d-6

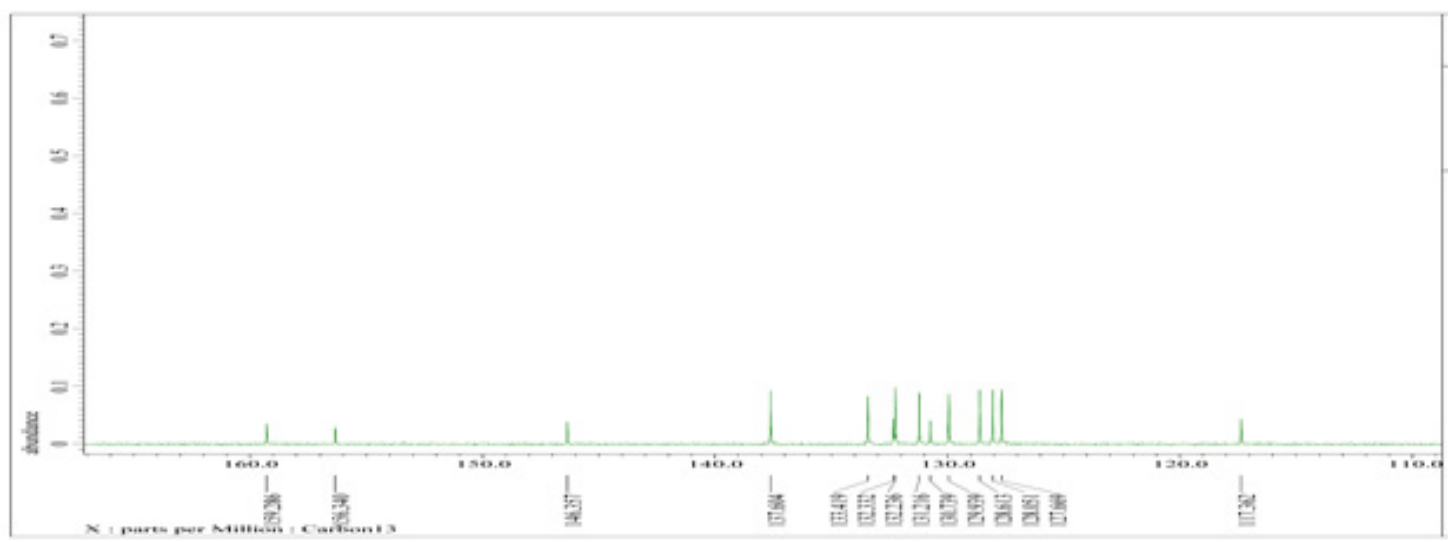

Figure 3. NMR-C spectra of 2-(2-chlorophenyl)-4H-benzo[d][1,3]oxazin-4-one in DMSO d-6

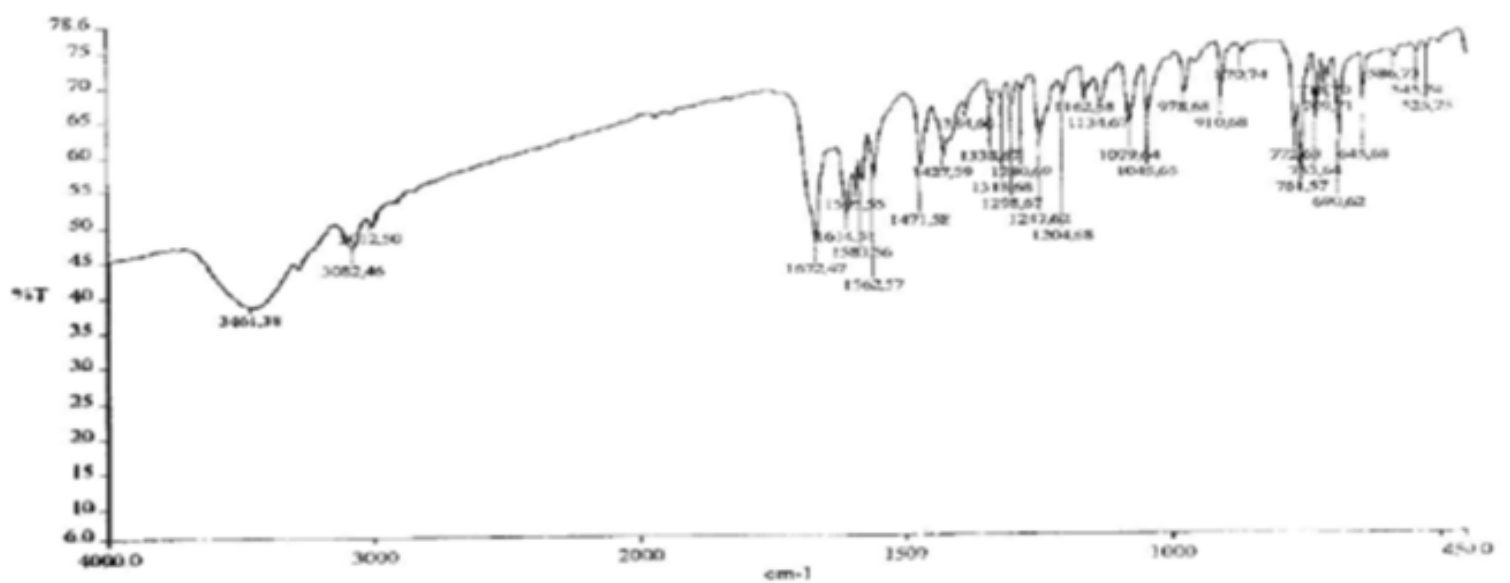

Figure 4. IR spectra of spektra IR senyawa 3-amino-2-(2-chlorophenyl)quinazolin-4(3H)-one

\section{Discussion}

In the first step of the reaction, anthranilic acid was reacted with 2-chlorobenzoyl chloride in pyridine, then 2-(2-chlorophenyl)-4H-benzo[d] [1,3] oxazin-4-one was obtained. This reaction occured by $\mathrm{N}$-acylation via dehydrative cyclization mechanism [2-4].

The second reaction occured between 2-(2-chlorophenyl)4H-benzo[d][1,3]oxazin-4-one and hydrazine hydrate to obtain 3-amino-2-(2-chlorophenyl)quinazolin-4(3H)-one. This reaction began with nucleophillic attacking from hydrazine to the carbonyl group of lactone rings. This reaction formed an open-ring compound of 2-chloro-N-(2 (hydrazinecarbonyl) phenyl)benzamide. A long-term heating exposure and pyridine support caused intramolecular reaction, forming quinazoline rings of 3-amino-2-(2-chlorophenyl)quinazolin-4(3H)-one [3] . In this reaction, an alternative methodology for the synthesis using microwave was used. This method was more convenient and time-saving since it only took 5 minutes using 800 watts of microwave power, whereas conventional method took 10 hours for the reaction. It was found that using microwave irradiation in synthesis of 3-amino-2-(2-chlorophenyl)quinazolin-4 $(3 \mathrm{H})$ one improved the percentage yields $(87 \%)$ if compared with conventional heating $(79 \%)$. 


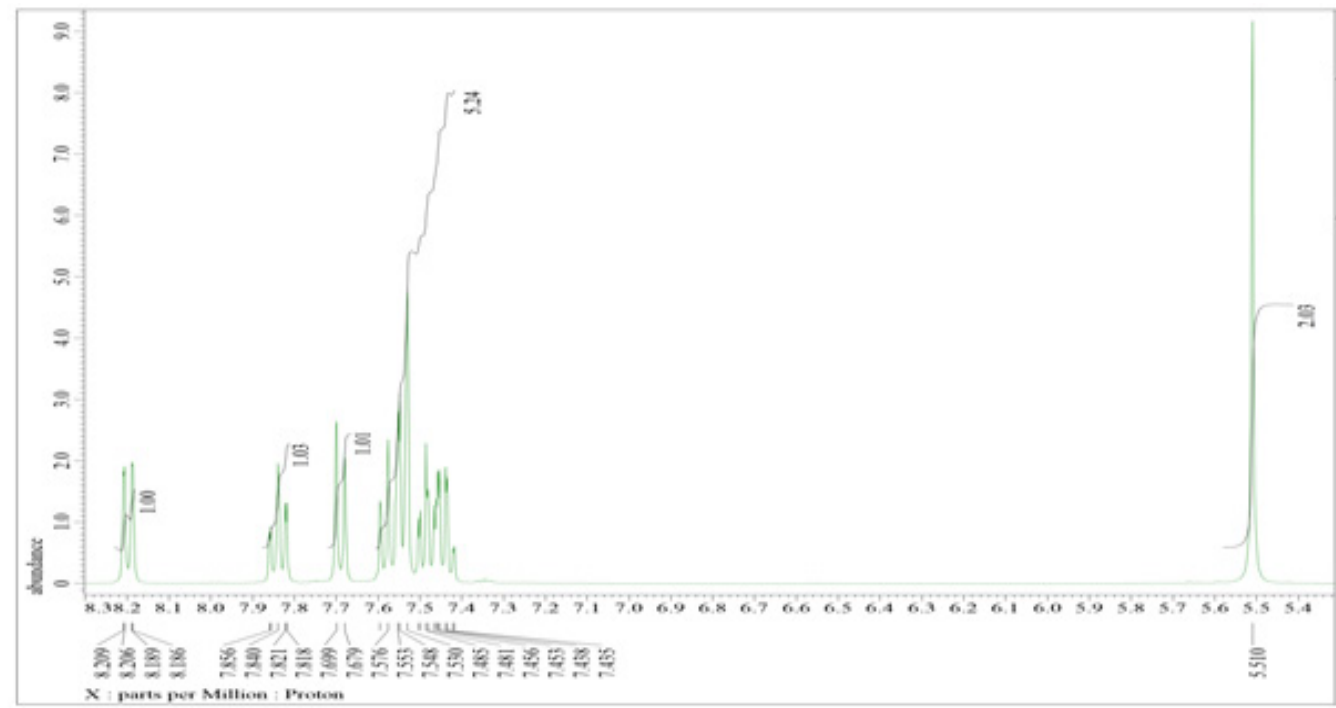

Figure 5. NMR-H spectra of 3-amino-2-(2-chlorophenyl)quinazolin-4(3H)-one in DMSO d-6

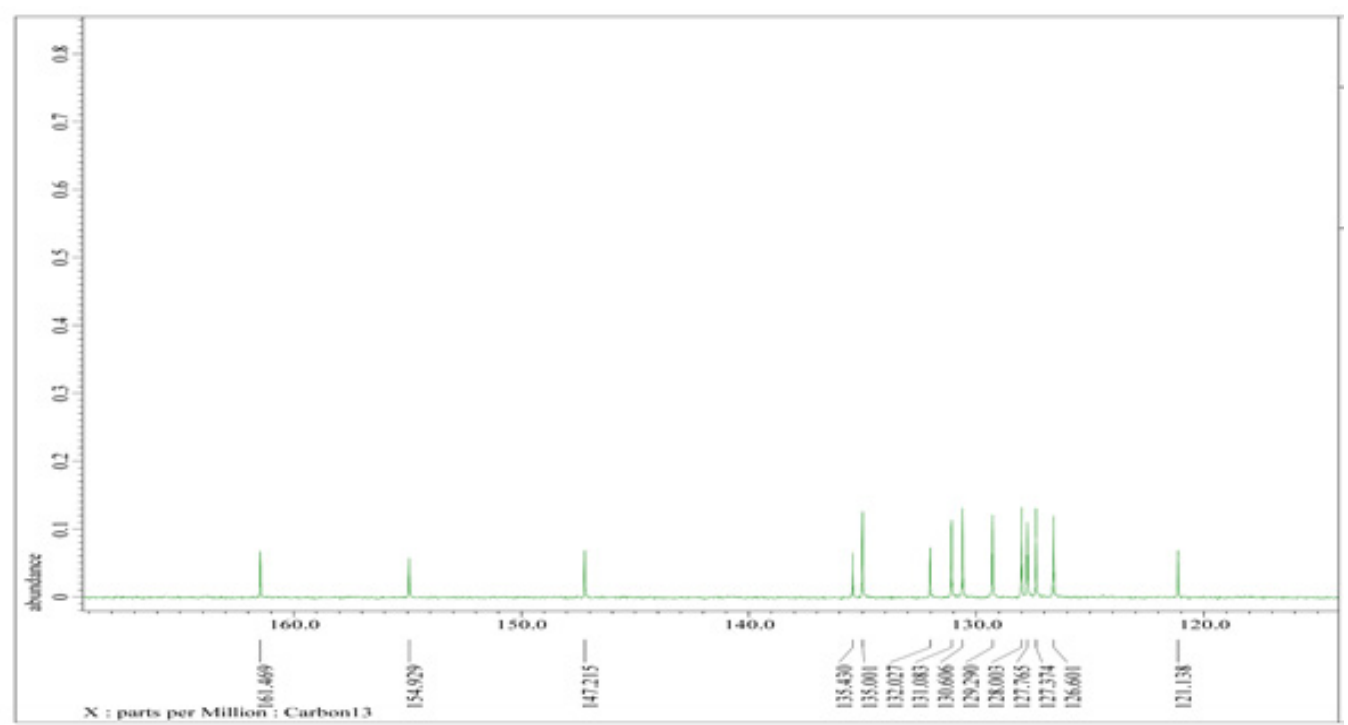

Figure 6. NMR-C spectra of 3-amino-2-(2-chlorophenyl)quinazolin-4(3H)-one in DMSO d-6

Table 1. Yields and total reaction time for synthesised 3-amino-2-(2-chlorophenyl) quinazolin-4(3H)-one

\begin{tabular}{|c|c|c|c|c|}
\hline \multirow{2}{*}{$\begin{array}{l}\text { Repli- } \\
\text { cation }\end{array}$} & \multicolumn{2}{|c|}{$\begin{array}{c}\text { Conventional } \\
\text { heating }\left(115^{\circ} \mathrm{C}\right)\end{array}$} & \multicolumn{2}{|c|}{ Microwave, 800W } \\
\hline & $\begin{array}{l}\text { Time } \\
\text { (hour) }\end{array}$ & $\begin{array}{l}\text { Yield } \\
(\%)\end{array}$ & $\begin{array}{c}\text { Time } \\
\text { (minutes) }\end{array}$ & Yield $\mathbf{( \% )}$ \\
\hline 1 & 10 & 76,2 & 5 & 84,2 \\
\hline \multirow{2}{*}{$\begin{array}{l}2 \\
3\end{array}$} & 10 & 79,8 & 5 & 87,2 \\
\hline & 10 & 80,1 & 5 & 90,5 \\
\hline
\end{tabular}

\section{Conclusion}

The results of the study suggested that there was an improvement in percent yields of 3-amino-2-(2-chlorophenyl) quinazolin- $4(3 \mathrm{H})$-one and a drastic reduction in total reaction time when performing microwave-assisted synthesis.

\section{References}

[1] K. Saurav, M. Garima, S. Pradeep, K. K. Jha, R. L. Khosa, and S. K. Gupta 2011 Quinazoline-4-one: a highly important hetrocycle with diverse biological activities, Der Chemica Sinica 436

[2] Kumar K. S., S.Ganguly, P. VijaiPandi, R.Veerasamy, and B. Jan. Synthesis 2012 Antiviral and Cytotoxic Investigations of 2-(4-chlorophenyl)-3-substituted quinazolin- $4(3 \mathrm{H})$ ones. International Journal of Drug Design and Discovery 3702

[3] Noolvi, Malleshappa N. , Harun M. Patel. 2013 Synthesis, method optimization, anticancer activity of 2,3,7-trisubstituted Quinazoline derivatives and targeting EGFR-tyrosine kinase by rational approach. Arabian Journal of Chemistry 635

[4] Noolvi, M.N., Patel, H.M., Bhardwaj, V.B. 2011 An approach to design anticancer agents by 2D QSAR studies on a series of quinazoline analogues as tyrosine kinase (erbB-2) inhibitors. 711

[5] Lindsorm, P., Tierney,L., Wathey, B., dan Wstman, J. 2001 Microwave Assisted Organic Synthesis - A review. Tetrahedron. 519225 